cern with what I have termed the temporal orientations of different kinds of analysis (see Miyazaki 2003, 2004). To rephrase her observations in my own terms, both Schutz's and Searle's reflections on the temporal sequence of intention and action, on the one hand, and statisticians' retrospectively discovered uncertainty, on the other, fail to recover the real-time immediacy of Cameroonian women's sense of uncertainty. I wonder, however, if Johnson-Hanks has fully explored the implications of this insight for the temporality of her own analysis. Her critique of philosophy and statistics invites further questions about her own discipline and its method. In particular, I wonder if she is willing to consider how one can recapture the immediacy of actors' sense of temporality in an inevitably retrospective ethnographic description. For example, one opportunity that she could exploit more fully concerns Cameroonian women's sense of radical change. According to Johnson-Hanks, these women interpret the current heightened state of uncertainty surrounding their lives as a consequence of Cameroon's political and economic crisis. But what is interesting is that their explicit rejection of planning as a modality of engagement with the world is framed as a response to a new situation. Johnson-Hanks is absolutely right in not taking for granted these women's invocation of newness; she sees in their characterization of the nature of the world both continuity with and discontinuity from the well-documented Beti conception of personhood and time. However, I wonder if there is something more to Cameroonian women's insistence that the world has changed. In emphasizing that they can no longer make plans and choices for the future, perhaps these women are drawing attention to the facticity of radical change itself as much as the realness of the uncertainty of the world. From this point of view, by treating the discourse of crisis as a framing device for the subject of uncertainty Johnson-Hanks may inadvertently have erased the reality of these women's apprehension of change and newness. In light of the current pervasive interest in open-ended, provisional, and emergent forms of analysis in anthropology and other social sciences (see, e.g., Ong and Collier 2005), it would be interesting to consider what an analysis would look like if one emulated Cameroonian women's concern with "getting by."

\section{CATRIEN NOTERMANS}

Department of Cultural Anthropology, Radboud

University Nijmegen, Comeniuslaan 4, $6525 \mathrm{HP}$

Nijmegen, The Netherlands (c.notermans@maw.ru.nl). 23 XII 04

I greatly welcome Johnson-Hanks's criticism of the usefulness of Western modes of analysis for explaining women's reproductive futures in Cameroon. During several periods of fieldwork in eastern Cameroon I also discussed marriage and motherhood, and I recognize the narrative dimension of women's attitudes towards longterm planning that she mentions. I fully share her concern about the disjunctures and discontinuities between qualitative and quantitative data; statistics often fail to capture women's opinions and worries about life. Whereas statistics want to talk "numbers," women want to tell "stories" in which numbers are flexible and negotiable. Though the statistical truth may give the impression of "telling the same story," women's life courses are much more dynamic and open to creativity than any statistics may discern. I agree with JohnsonHanks that women's uncertainty about possible futures does not make them powerless, passive, or incapable of defining their futures. They do have agency, and they constantly make choices in a rational strategic way; it is simply not our way.

Johnson-Hanks's objective of explaining women's uncertainty, however, seems to lack a kinship argument that may contribute to an understanding of that uncertainty. Johnson-Hanks generally connects women's unpredictable futures to the uncertain world of Cameroon at the end of the I99os and argues that people invoke the economic crisis as an explanation and excuse for the ambiguity and insecurity that they experience. As she admits, "there is no evidence that life prior to la crise was objectively more certain"; this idiom for describing uncertainty only partially explains the problem she discusses. Supplementary to her analysis of the inadequacies of a model of intentional action, I would like to focus not only on the crisis but also on the importance of kinship in women's lives. Whereas a (Eurocentric) rationalchoice model assumes persons to be autonomous individuals who aim at goals defined by self-interest, in Cameroon women's experiences and choices are rooted in a society that is saturated with kin relationships. To understand women's uncertainty we must think of women as "the site of a plurality of relationships" (Piot I999:7).

Throughout my research women stated again and again that from their first menstruation onwards, relatives never stopped emphasizing that the children they would bear in the future would be not for themselves but for the whole family. Since the number of children women will have depends on the agency and choices of relatives, women hesitate to answer questions such as "How many children do you plan to have?" A woman can hardly be sure about the number of children she will have to care for because relatives may claim her (biological) children as foster children at unpredictable moments throughout her life (Notermans 2004). When children are born in marriage, they may be claimed by their mother's husband and his sisters or brothers; when they are born out of wedlock, they may be claimed by their maternal grandmother or their mother's brothers and sisters "born from the same womb." Though women can counterbalance this loss of biological children by claiming foster children from their brothers or sisters, the outcome cannot be predicted, as life circumstances change over time. A married woman will judge the desired number of children differently from an unmarried one. Moreover, a woman with a good marriage will judge child numbers differently from one facing divorce.

Beyond the interdependent agency of women and their relatives, conjugal flexibility also has to be considered 
in explaining women's "failure" to plan their futures. Women's life courses are often characterized by a high frequency of divorce and a sequence of formal and informal marriages. Selecting and entering into different relationships simultaneously and successively in different stages of life, women attempt to pursue their best opportunities. Moving between the households of formal husbands, informal husbands, mothers, and brothers, women live like nomads in a wide network of kin relationships. This posture of openness of possibility engenders different attitudes to child numbers at different moments of life.

Comparing ethnographic studies on women's reproductive lives in Cameroon can help us understand women's lives and interpret their different and often surprising attitudes towards life. I would like to continue the dialogue with Johnson-Hanks, but we'll see "what the future decides."

\section{SARA RANDALL \\ Department of Anthropology, University College London, Gower St., London WCIE 6BT, U.K. \\ (s.randall@ucl.ac.uk). Io I o5}

Johnson-Hanks is to be congratulated for this elegant combination of ideas emerging from philosophy, ethnography, and statistics to investigate a subject that has been the backbone of much demographic research in recent years and the foundation for much policy and action but has caused unease amongst many demographers, particularly those who combine qualitative with quantitative approaches. For those of us unfamiliar with philosophical thought this paper clarifies where our unease may lie. Although the many demographic surveys on fertility intentions and ideal family size come up with plausible numerical outcomes, such numbers may not adequately reflect the responses obtained with other research methodologies in which uncertainty, non-numerical responses, and evasion are much more frequent. Johnson-Hanks's plausible discussions of the reasons Cameroonian women respond in such ways will ring true to many others who work in this field and should make demographers challenge many international demographic and health survey findings. However, I would have liked to see this aspect taken farther. Her comment that most of her sample (of well-educated Cameroonian women) provided "non-numeric" responses to her questions on reproductive intentions raises the question why most surveys produce so few such responses, especially for such categories of women. How do the enumerators move from the initial non-numerical responses to the recorded numerical ones? Were such movements evident in the interviews with these respondents?

Johnson-Hanks honestly articulates some her own preconceptions before undertaking the research and the consequences of these preconceptions in generating "some extremely inelegant interviews." Her subsequent understanding and reformulation of women's responses is very convincing but still depends substantially on accepting the articulated responses from such interviews (whether inelegant or elegant) as representing women's experiences and their judicious opportunism. While not denying the plausibility of her interpretation, it would be useful to have more discussion of the forces influencing "how they elect to present their thoughts in an interview" and thus the conclusions that can be drawn. To a degree this is confronted through contrasting the Cameroonian practice of referring to future trajectories using potential titles with Castle's work in Mali, which suggested that invoking future events may incur witchcraft or sorcery penalties. The stakes are very different, however: referring to others' futures through titles poses low risks to the individual respondent compared with those invoked by intimating plans for one's own (and one's children's) future. Difficulties in accepting statements about future reproductive plans at face value are compounded elsewhere in Muslim Africa (Senegal and Mali, for example) by strong social sanctions against challenging divine will with respect to giving children. Fear of crossing such boundaries can inhibit people from expressing any ideas which suggest such forward planning: in interview contexts it can be extremely difficult to interpret silence-to differentiate ideas which have never been thought from those which should not be expressed. There is certainly evidence elsewhere in the paper that similar associations between divine will and childbearing operate in Cameroon, and therefore it is essential to consider the evasive answers to fertilityplanning questions not just in terms of uncertainty but also in terms of the respondent-interviewer relationship and the acceptability of publicly stating private intentions.

DIANNA J . SHANDY

Department of Anthropology, Macalester College, Carnegie Hall o4, I600 Grand Ave., St. Paul, MN 55I05, U.S.A. (shandy@macalester.edu). I I I 05

This paper advances the notion of "judicious opportunism" to explain social action under conditions of uncertainty in contemporary Africa. It is significant in providing a means of theorizing social action in African settings in ways that avoid what Mudimbe (I988) identifies as the ideological construction of Africa and Africans as prone to decisions based on emotion or reaction rather than on rationality, objectivity, or long-term planning.

Taking the mismatch between a standardized demographic survey question and Cameroonian women's responses as a point of departure, Johnson-Hanks mounts an effective challenge to a dominant model in reproductive-policy circles and exposes the futility of international aid agencies' quest to elicit "the reproductive intentions of women in poor countries." She makes a compelling case that the limited and limiting question of how many children a woman plans to have falls short of apprehending the complex social, political, and economic realities that inform reproductive outcomes. 